\title{
Orthodontic treatment need among young Saudis attending public versus private dental practices in Riyadh
}

This article was published in the following Dove Press journal:

Clinical, Cosmetic and Investigational Dentistry

3 November 2016

Number of times this article has been viewed

\author{
Asma M Al-Jobair ${ }^{1,2}$ \\ Laila F Baidas ${ }^{1,2}$ \\ Anfal A Al-Hamid ${ }^{2}$ \\ Sara G Al-Qahtani \\ Amani T Al-Najjar ${ }^{2}$ \\ Huda M Al-Kawari ${ }^{1,2}$ \\ 'Department of Pediatric Dentistry \\ and Orthodontics, ${ }^{2}$ College of \\ Dentistry, King Saud University, \\ Riyadh, Saudi Arabia
}

Objective: To assess and compare the severity of malocclusion and orthodontic treatment need among young Saudis receiving free treatment at public dental practices versus those paying for treatment at private practices.

Materials and methods: This retrospective study evaluated the records of 300 patients (179 females, 121 males; age 13-21 years) treated at orthodontic clinics from 2013 through 2015. The public sample was selected from orthodontic clinics at the College of Dentistry, King Saud University (KSU); the private sample was selected from five private orthodontic clinics in Riyadh, Saudi Arabia. The records were examined for the severity of malocclusion and for orthodontic treatment need using the Dental Health Component of the Index of Orthodontic Treatment Need. The prevalence of each occlusal discrepancy and the Dental Health Component grade were recorded. The severity of malocclusion and orthodontic treatment need were compared between practice types, age groups, and sexes with the chi-square test.

Results: Displacement, increased overjet, and Class II and III malocclusion were the most common orthodontic problems in this study. Patients attending public clinics at KSU generally had more severe malocclusion than the patients attending private clinics. Seventy-seven percent of orthodontically treated patients at KSU clinics were in great need of treatment, compared with $58.5 \%$ of patients treated at private clinics $(P=0.003)$. Among the patients with great treatment need, approximately $62 \%$ of male patients and $70 \%$ of patients $\leq 16$ years of age were treated at KSU clinics, compared with $38 \%$ and $48 \%$, respectively, treated at private clinics $(P<0.0001)$. Conclusion: Young Saudis receiving free orthodontic treatment at public clinics at KSU had more severe malocclusion with greater need of orthodontic treatment than the patients paying for treatment at private clinics.

Keywords: malocclusion, orthodontic treatment need, IOTN, public, private

\section{Introduction}

Esthetic considerations and dental appearance have become very important for children and adolescents, who are therefore strongly motivated to seek orthodontic treatment. ${ }^{1}$ The number of children and adolescents seeking orthodontic treatment has dramatically increased over the past few decades; however, not all of these patients have true orthodontic problems. ${ }^{2}$ The patient's perception, parents' perceptions, and orthodontist's assessment all influence the need for orthodontic treatment in children and adolescents. Several studies have shown that there is no link between actual need for treatment as assessed by orthodontists and perceptive need as evaluated by patients or their parents, unless the condition is symptomatic. ${ }^{3-6}$ With the increased demand for orthodontic treatment, free health services need a quantifiable method of assigning
Correspondence: Asma M Al-Jobair Department of Pediatric Dentistry and Orthodontics, College of Dentistry, King Saud University, 60169, Riyadh II545, Saudi Arabia

Email aaljobair@ksu.edu.sa 
resources. ${ }^{7}$ Accordingly, several orthodontic treatment need indices have been developed to help to estimate treatment need and improve consistency in treatment provision, ${ }^{7}$ such as the Index of Orthodontic Treatment Need (IOTN); ${ }^{8}$ the Dental Aesthetic Index; ${ }^{9}$ the Index of Complexity, Outcome and Need; ${ }^{10}$ and the Peer Assessment Rating Index. ${ }^{11}$ These scalebased indices are used to evaluate the severity of malocclusion and orthodontic treatment need. However, each method has its limitations: most treatment need indices do not assess the prognosis of untreated malocclusions and related symptoms, and these indices may need revalidation overtime., ${ }^{72}$

The IOTN, introduced by Brook and Shaw in 1989, consists of two components, the Aesthetic Component and the Dental Health Component (DHC). ${ }^{8}$ The IOTN has been comprehensively compared with other treatment need indices and has been found to be accurate, valid, and reproducible, with high sensitivity and specificity. ${ }^{13-15}$ Past studies have used various indices to investigate orthodontic treatment need in different populations. The IOTN is most frequently used, especially among researchers in the Middle and Far East. Based on the DHC of the IOTN, a lower percentage of treatment need has been reported among children in Egypt $(19.8 \%),{ }^{16}$ India (21\%), ${ }^{17}$ Saudi Arabia (22.4\%), ${ }^{18}$ Kuwait $(28 \%),{ }^{19}$ and Jordan $(28 \%)^{20}$ than among Iranian $(36.1 \%),{ }^{21}$ Turkish (38.8\%), ${ }^{22}$ Pakistani (40\%), ${ }^{23}$ Malaysian (47.9\%), ${ }^{24}$ and Chinese $(52 \%)^{25}$ populations.

Orthodontic treatment is expensive, with many factors influencing its cost, such as case difficulty, length of treatment, insurance coverage, and clinic location, among others. ${ }^{26}$ In Saudi Arabia, governmental institutions, including the Ministry of Health, military hospitals, and academic institutions, provide free orthodontic treatment to the public. This free service potentially allows patients with little treatment need to be treated, displacing others with greater need. Consequently, this system can generate waiting lists extending for many years, even for patients with severe malocclusion and mandatory treatment need. It has been shown that severe malocclusion affects the quality of life of Saudi children. ${ }^{27,28}$ At the same time, providing free orthodontic treatment can result in a heavy work load for public health care providers. ${ }^{4}$ In 2006, Hassan ${ }^{4}$ examined orthodontic treatment need according to the DHC of the IOTN among adults who were referred for orthodontic treatment at King Abdulaziz University (KAU) in Jeddah, Saudi Arabia, and compared that need with that of patients at private dental clinics. ${ }^{4} \mathrm{He}$ found that the proportion of patients with little to no treatment need was significantly higher at KAU clinics than at private clinics. In contrast, the proportion of patients with great treatment need was significantly higher at private clinics than at KAU clinics. ${ }^{4}$

In countries with publicly funded orthodontic services, orthodontic treatment priority is determined by the severity of malocclusion and the need for treatment. Since its development in 1990, the IOTN has been used by the National Health Service in the UK to limit access to orthodontic care; since 2006, the IOTN has defined which patients will receive National Health Service treatment in primary care. ${ }^{29}$ In Finland, publicly funded dental treatment, including orthodontic treatment, has been provided to residents up to 18 years of age. The Finnish National Board of Health recommends the ten-grade Treatment Priority Index to select patients for orthodontic treatment. ${ }^{30,31}$ In Saudi Arabia, there are no national regulations guiding the extent of public orthodontic care, and no rationing of access to care according to the severity of malocclusion has been implemented.

Providing free, high-quality orthodontic services in Saudi Arabia, such as the services provided at the College of Dentistry at King Saud University (KSU), as well as estimating the resources and workforce necessary to provide these services, requires careful evaluation of the true need for orthodontic treatment in this country. Therefore, the objective of this retrospective study was to use the DHC of the IOTN to assess and compare the severity of malocclusion and orthodontic treatment need among young Saudis receiving free treatment at public orthodontic clinics versus those paying for treatment at private dental clinics.

\section{Materials and methods}

At an alpha of 0.05 with a maximum difference of 0.4 , and with an estimated standard deviation of one with a power of 0.85 , the necessary sample size was estimated to be at least 114 study subjects in each group.

After study approval was obtained from the Ethical Committee of the College of Dentistry Research Center at KSU, the preorthodontic records (orthodontic files, pretreatment study models, and panoramic radiographs) of 300 orthodontically treated patients aged 13-21 years were studied. Patient consent was not required by the Ethical Committee of the College of Dentistry Research Centre at KSU as patient data were kept unidentified. One hundred sixty-five orthodontic records were collected from the orthodontic department at the College of Dentistry at KSU, the oldest and largest public university in Riyadh. KSU houses a large orthodontic department in the College of Dentistry with more than 20 orthodontists. One hundred thirty-five orthodontic records were collected from five randomly selected private orthodontic clinics in different 
administrative areas in Riyadh. Lists of orthodontically treated patients from 2013 through 2015 were obtained and patients who fulfilled the inclusion criteria were selected. The following inclusion criteria were used: Saudi patients aged 13-21 years with preorthodontic records, patients currently under orthodontic treatment by orthodontists, patients with orthodontic records of good quality, patients treated with fixed appliances, and those with no history of previous orthodontic treatment.

The study models were examined to determine the severity of malocclusion and orthodontic treatment need based on the DHC of the IOTN. ${ }^{8}$ The DHC is classified into five grades ranging from Grade 1 (no treatment need) to Grade 5 (extreme treatment need). Two examiners were trained and calibrated by an expert orthodontist to use the DHC of the IOTN at the College of Dentistry, KSU. Data from study models were collected using the acronym "MOCDO" (missing teeth, overjet, crossbite, displacement of contact points, overbite) to identify the most severe occlusal trait of each patient. In addition, the Angle molar classification was recorded. Panoramic radiographs were examined to confirm the presence of hypodontia, supernumerary teeth, and impactions.

The data were analyzed with Statistical Package for Social Sciences 20 software (IBM Corporation, Armonk, NY, USA). The incidence of each occlusal trait and the DHC of the IOTN grade were calculated. The final overall score for IOTN category from Grade 1 to Grade 5 was recorded according to the most severe trait. Treatment need was categorized as no or little need (Grades 1 and 2), borderline need (Grade 3), or treatment required (Grades 4 and 5). The sample was divided into two age groups ( $\leq 16$ years and $>16$ years). We compared the severity of malocclusion and orthodontic treatment need at the two types of dental practice and between age groups and sexes using the chi-square test. $P$-values $<0.05$ were considered significant. A kappa test was used to confirm intra- and interexaminer reliability.

\section{Results}

Intraexaminer reliability was good to excellent, with kappa values of $0.89-0.95$. Kappa testing also showed good interexaminer reliability, with a value of 0.84 .

Three hundred preorthodontic records were selected and examined. Approximately $58 \%$ of the sample was $\leq 16$ years of age (mean, 15.9 \pm 2.7 years). The sample included 179 study models from female patients $(59.7 \%)$ and 121 from male patients $(40.3 \%)$. There were no significant differences in the distribution of age or sex between the practices $(P>0.05)$.

Table 1 shows the incidence of various orthodontic problems among the patients. The most common orthodontic problem was displacement (96\%), followed by increased overjet (64.7\%), Class II or III molar relationship (64\%), crossbite (36\%), overbite (36\%), and open bite (31\%). Approximately $12.3 \%$ of the sample had congenitally missing teeth and $13.7 \%$ had retained deciduous teeth; however, impaction was relatively uncommon $(8.3 \%)$. The incidence of cleft lip and palate was $3.3 \%$.

The distribution and severity of orthodontic problems among patients attending each type of practice are shown in Table 2. Approximately $77 \%$ of patients treated at KSU clinics had Class II or III malocclusion, compared with $48 \%$ of patients at private clinics; this difference was statistically significant $(P<0.0001)$. A significant difference was also found in the severity of tooth displacement among treated patients between the practice types $(P<0.0001)$. Approximately

Table I The incidence of the orthodontic problems among the sample as assessed by the DHC of the IOTN

\begin{tabular}{|c|c|c|c|c|c|c|c|}
\hline Orthodontic problem & No. of cases $=300$ & Incidence \% & Grade I & Grade 2 & Grade 3 & Grade 4 & Grade 5 \\
\hline Class II and III & 192 & 64 & & & & & \\
\hline Displacement & 288 & 96 & 10 & 28 & 33 & 25 & \\
\hline Crossbite (anterior or posterior) & 108 & 36 & & 5.7 & 20 & 10.3 & \\
\hline Open bite & 93 & 31 & & 19 & 7 & 5 & \\
\hline Overbite & 108 & 36 & & 19.3 & I I.7 & 5 & \\
\hline Overjet & 194 & 64.7 & & 33.7 & 16 & 10.3 & 4.7 \\
\hline $\begin{array}{l}\text { Reverse overjet (all four incisors in } \\
\text { crossbite) }\end{array}$ & 30 & 10 & & & & 10 & \\
\hline Partially erupted & 68 & 22.7 & & & & 22.7 & \\
\hline Supernumerary & 4 & 1.3 & & & & 1.3 & \\
\hline Hypodontia & 37 & 12.3 & & & & 11.2 & I.I \\
\hline Impaction & 25 & 8.3 & & & & & 8.3 \\
\hline Retained deciduous & 41 & 13.7 & & & & & 13.7 \\
\hline $\mathrm{CL} / \mathrm{P}$ & 10 & 3.3 & & & & & 3.3 \\
\hline Other craniofacial anomalies & 2 & 0.6 & & & & & 0.6 \\
\hline
\end{tabular}

Abbreviations: CL/P, cleft lip/palate; DHC, Dental Health Component; IOTN, Index of Orthodontic Treatment Need. 
Table 2 Distribution and severity of orthodontic problems among patients attending public (KSU) versus private clinics

\begin{tabular}{|c|c|c|c|c|}
\hline \multirow[t]{2}{*}{ Orthodontic problems } & \multirow{2}{*}{$\begin{array}{l}\text { Public (KSU) } \\
\text { No. (\%) }\end{array}$} & \multirow{2}{*}{$\begin{array}{l}\text { Private } \\
\text { No. (\%) }\end{array}$} & \multirow[t]{2}{*}{ Chi-square } & \multirow[t]{2}{*}{$P$-value } \\
\hline & & & & \\
\hline \multicolumn{5}{|l|}{ Molar occlusion $(n=300)$} \\
\hline Class I & $38(23)$ & $70(51.9)$ & & \\
\hline Class II & $68(4 \mid .2)$ & $27(20)$ & 29.013 & $<0.0001$ \\
\hline Class III & $59(35.8)$ & $38(28.1)$ & & \\
\hline \multicolumn{5}{|l|}{ Displacement $(n=288)$} \\
\hline Slight (Grades I and 2) & $38(23.3)$ & $76(60.8)$ & & \\
\hline Moderate (Grade 3) & $72(44.2)$ & $27(21.6)$ & 42.443 & $<0.0001$ \\
\hline Severe (Grade 4) & $53(32.5)$ & $22(17.6)$ & & \\
\hline \multicolumn{5}{|l|}{ Overjet $(n=194)$} \\
\hline Slight (Grade 2) & $76(52.1)$ & $25(52.1)$ & & \\
\hline Moderate (Grade 3) & $39(26.7)$ & $9(18.8)$ & 1.906 & 0.386 \\
\hline Severe (Grades 4 and 5) & $31(21.2)$ & $14(29.2)$ & & \\
\hline \multicolumn{5}{|l|}{ Open bite $(n=93)$} \\
\hline Slight (Grade 2) & $40(66.7)$ & $17(51.5)$ & & \\
\hline Moderate (Grade 3) & $7(11.7)$ & $14(42.4)$ & 12.932 & 0.002 \\
\hline Severe (Grade 4) & $13(21.7)$ & $2(6.1)$ & & \\
\hline \multicolumn{5}{|l|}{ Crossbite $(n=108)$} \\
\hline Slight (Grade 2) & $10(16.4)$ & $7(14.9)$ & & \\
\hline Moderate (Grade 3) & $36(59)$ & $24(5 I .1)$ & 1.166 & 0.558 \\
\hline Severe (Grade 4) & $15(24.6)$ & $16(34)$ & & \\
\hline \multicolumn{5}{|l|}{ Overbite $(n=108)$} \\
\hline Slight (Grade 2) & $43(58.1)$ & $15(44.1)$ & & \\
\hline Moderate (Grade 3) & $21(28.7)$ & $14(4 \mid .2)$ & 2.050 & 0.359 \\
\hline Severe (Grade 4) & $10(13.5)$ & $5(14.7)$ & & \\
\hline \multicolumn{5}{|c|}{ Eruption-associated problems $(n=159)$} \\
\hline Yes (Grades 4 and 5) & $109(66.1)$ & $50(37)$ & 25.109 & $<0.0001$ \\
\hline
\end{tabular}

Abbreviation: KSU, King Saud University.

Table 3 Distribution of orthodontic problems among patients according to orthodontic treatment need

\begin{tabular}{|c|c|c|c|c|}
\hline \multirow[t]{3}{*}{ Orthodontic problem } & \multicolumn{4}{|l|}{ Treatment need } \\
\hline & $\begin{array}{l}\text { Little/no Tx. (Grades I and 2) } \\
n=39\end{array}$ & $\begin{array}{l}\text { Borderline Tx. (Grade 3) } \\
n=55\end{array}$ & $\begin{array}{l}\text { Need Tx. (Grades } 4 \text { and 5) } \\
n=206\end{array}$ & Total \\
\hline & No. (\%) & No. (\%) & No. (\%) & No. (\%) \\
\hline Class II and III & $20(10.4)$ & $40(20.8)$ & $132(68.7)$ & $192(100)$ \\
\hline Displacement & $37(12.8)$ & $50(17.4)$ & $20 \mathrm{I}(69.8)$ & $288(100)$ \\
\hline Crossbite & $8(7.4)$ & $21(19.5)$ & $79(73.1)$ & $108(100)$ \\
\hline Open bite & $3(3.2)$ & $9(9.7)$ & 81 (87.I) & $93(100)$ \\
\hline Overbite & $7(6.5)$ & $20(18.5)$ & 81 (75) & $108(100)$ \\
\hline Overjet & $18(9.3)$ & $26(13.4)$ & I $50(77.3)$ & $194(100)$ \\
\hline
\end{tabular}

Abbreviation: Tx, treatment.

$61 \%$ of patients treated at private clinics had slight tooth displacement, compared with $23.3 \%$ of patients treated at KSU clinics. In addition, significantly more patients with eruption-associated problems, such as hypodontia, retained deciduous teeth, impactions, and cleft lip and palate, were treated at KSU clinics than at private clinics $(P<0.0001)$. Similarly, a significantly higher percentage of patients treated at KSU clinics had severe open bite (21.7\%), compared with only $6.1 \%$ of patients treated at private clinics $(P=0.002)$. In contrast, there were no differences between practices in the percentages of patients with increased overjet, crossbite, or over bite, regardless of severity $(P>0.05)$. The distribution of orthodontic problems according to orthodontic treatment need is shown in Table 3. Most of the orthodontic problems were recorded in patients with great need of orthodontic treatment; however, open bite, increased overjet, and increased overbite were most commonly observed.

Among the patients, $13 \%$ had no or slight treatment need, $18.3 \%$ had moderate to borderline need, and $68.7 \%$ had great treatment need. Comparison of DHC grades between the KSU group and the private group revealed a significant difference in treatment need $(P=0.003)$ (Figure 1). Seventy-seven 


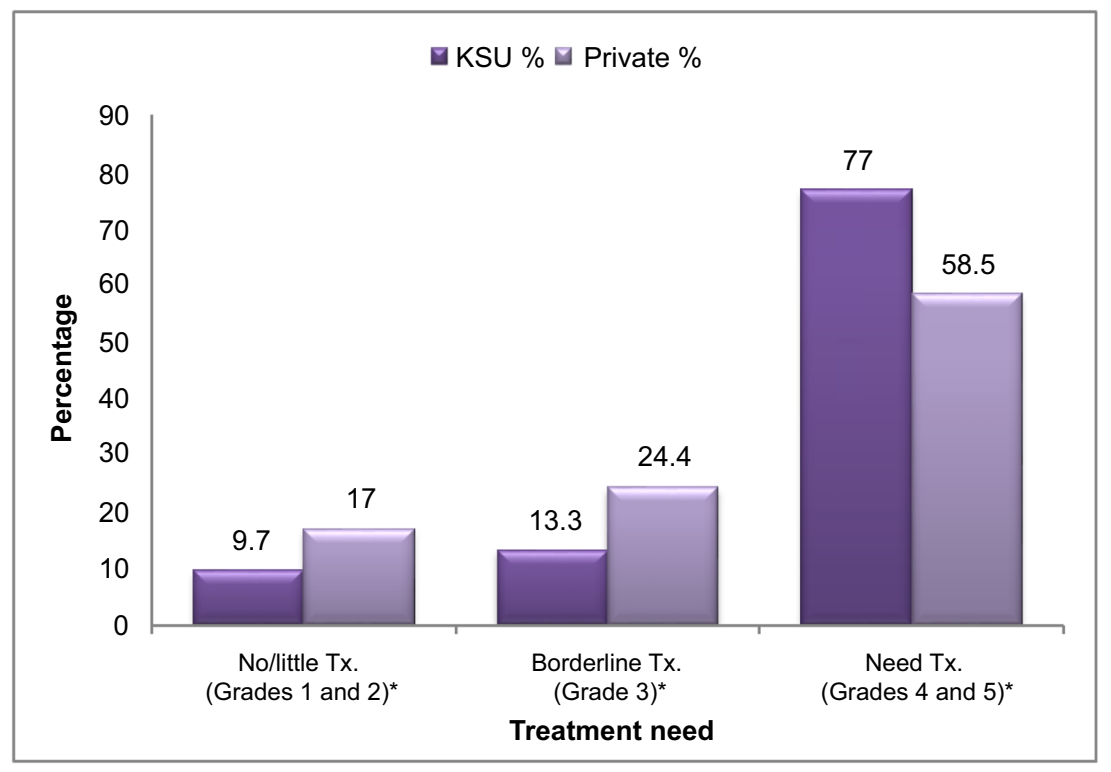

Figure I Comparison of orthodontic treatment need (DHC) among patients attending public (KSU) versus private clinics. Note: $* P=0.003$.

Abbreviations: DHC, Dental Health Component; KSU, King Saud University; Tx, treatment.

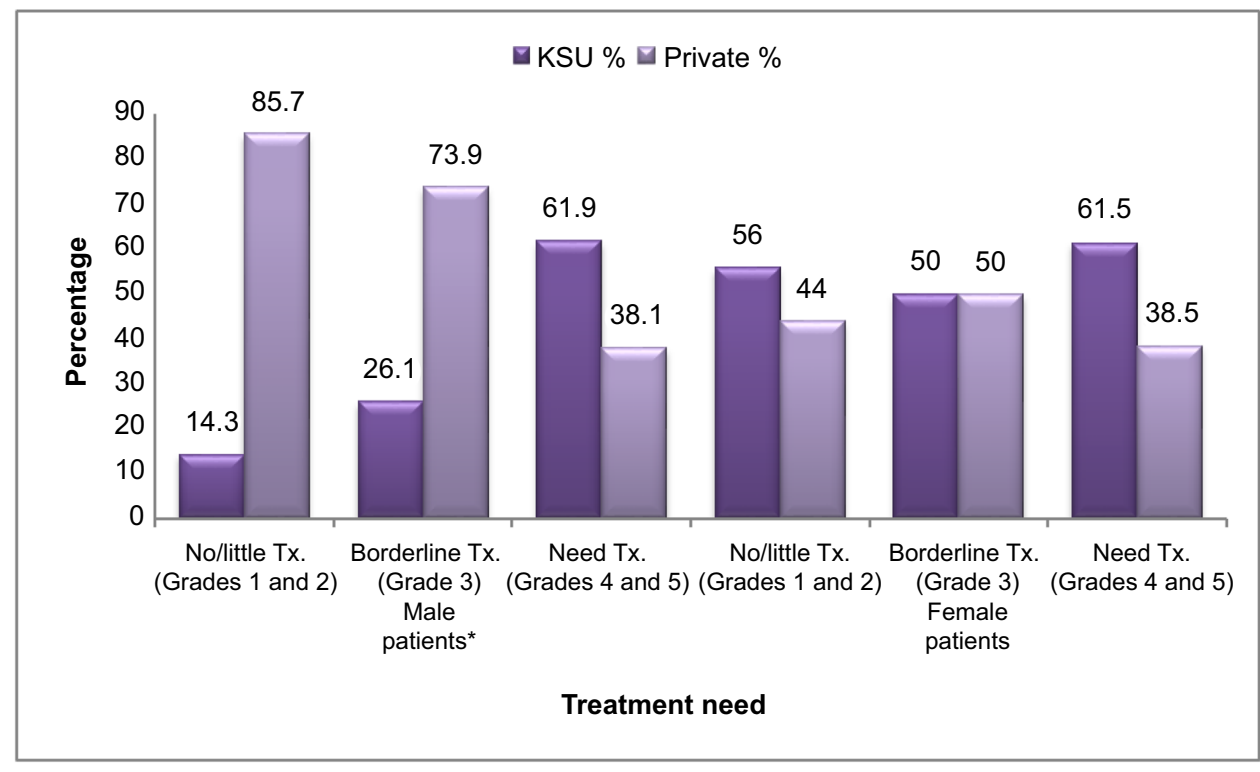

Figure 2 Comparison of orthodontic treatment need (DHC) among patients attending public (KSU) versus private clinics according to sex. Note: $* P<0.0001$.

Abbreviations: DHC, Dental Health Component; KSU, King Saud University; Tx, treatment.

percent of patients treated at KSU clinics were in great need of orthodontic treatment, compared with $58.5 \%$ of patients treated at private clinics. The percentage of patients with little to no treatment need (17\%) or borderline treatment need (24.4\%) was higher in the private group than in the KSU group (9.7\% and $13.3 \%$, respectively) (Figure 1).

In the current study, there was a significant difference in treatment need among male patients treated at KSU versus those treated at private clinics $(P<0.0001)$ (Figure 2). Most male patients with no, little, or borderline treatment need were treated at private dental clinics, while male patients with great treatment need were treated at KSU clinics. Similarly, most younger patients with no, little, or borderline treatment need were treated at private dental clinics, whereas young patients with great treatment need were treated at KSU dental clinics $(P<0.0001)$ (Figure 3).

\section{Discussion}

Demand for orthodontic treatment is expanding as awareness has increased in the growing population of Saudi Arabia. ${ }^{32}$ 


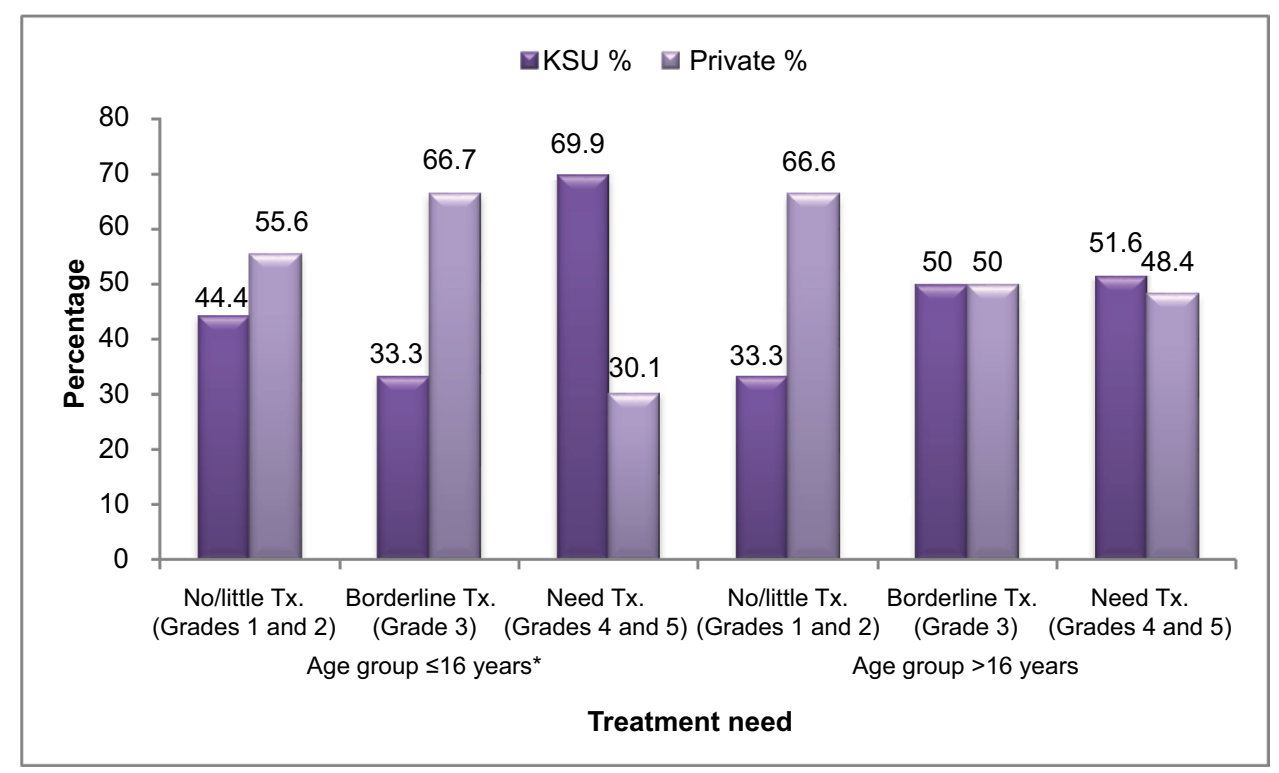

Figure 3 Comparison of orthodontic treatment need (DHC) among patients attending public (KSU) versus private clinics according to age group. Note: $* P<0.0001$.

Abbreviations: DHC, Dental Health Component; KSU, King Saud University; Tx, treatment.

However, several studies have indicated that patients overestimate their own treatment needs compared with the evaluation of orthodontists. ${ }^{3,4}$ The clinical skills of orthodontists allow much more accurate and comprehensive assessment of a patient's presenting condition than the patient's selfassessment. ${ }^{33}$ In the current study, the need for orthodontic treatment was evaluated based on orthodontic assessment, with the assumption that all patients perceived themselves as needing orthodontic treatment.

The IOTN was used in this study because it is valid, quick, reproducible, and easy to use. However, the IOTN is mainly designed for permanent teeth and its application in patients with mixed dentition may require modification. ${ }^{34}$ The IOTN is an excellent tool when used by experts in orthodontic research; however, a long training period is required before an examiner can use the index reliably. The modified IOTN appears to overcome the training and reliability problems that often accompany the use of orthodontic indices by nonspecialists in oral health surveys. ${ }^{35}$ Although widely used to grade several common occlusal traits, the IOTN has some limitations. For example, it does not assess the skeletal components of malocclusion and does not account for facial features, deformity, or soft-tissue conditions. ${ }^{36}$ In addition, there is no correlation between the IOTN grade of a presenting malocclusion and functional or quality-of-life improvement after treatment, and some of the functional indications for orthognathic treatment are not included. ${ }^{37}$ The Index of Orthognathic Functional Treatment Need was developed to overcome some of these limitations..$^{37,38}$
Approximately $60 \%$ of patients in the present study were females. In general, female patients seek orthodontic treatment more than male patients, a difference that reflects the greater concern about facial and dental appearance among females. ${ }^{39}$ In addition, this sex difference might be attributed to the earlier growth and development, and also greater selfconsciousness of females compared with males. ${ }^{2}$ More than half of the patients were younger than 16 years of age, which may indicate that younger adolescents are more concerned about their appearance, ${ }^{39}$ or might be related to greater parental influence on their younger children, whereas older children might decide for themselves whether to pursue treatment.

The current study revealed information concerning the pattern of malocclusion among orthodontically treated patients. Malocclusion was mainly caused by displacement, increased overjet, crossbite, and overbite. Similar occlusal discrepancies were reported in a previous study of patients referred for orthodontic treatment at KAU. ${ }^{4}$ In a study of referred Pakistani patients, overjet, followed by crowding, were the most common occlusal traits associated with increased severity of malocclusion. ${ }^{40}$ The main occlusal traits found in patients who had a great need for orthodontic treatment were open bite, increased overjet, and overbite. Comparable findings were reported among Brazilian patients with great need for orthodontic treatment. ${ }^{41}$ Further, it was reported that the most common occlusal traits among Saudi children requiring orthodontic treatment were tooth displacement, increased overjet, and deep bite. ${ }^{28}$ Malocclusions characterized by open bite, severe overjet, and overbite can 
interfere with social relationships; facial appearance is considered the main reason for seeking orthodontic treatment. ${ }^{1}$

We found that orthodontic patients treated at KSU clinics had more severe malocclusions, such as severe displacement, Class II and III molar relationship, open bite, and problems associated with eruption, than the patients treated at private clinics. This difference could be related to different selection criteria for orthodontic treatment, or to the presence of different dental specialties at the dental college, which results in referral of difficult cases to its orthodontic clinics, whereas private patients usually refer themselves for treatment. In addition, this difference could be attributed to people's trust and confidence in the orthodontic treatment provided at KSU by qualified and skillful orthodontists accustomed to dealing with difficult situations. Furthermore, as KSU is a large teaching institution, it applies new treatment strategies based on recent research, making it an attractive choice for people with severe malocclusion seeking orthodontic treatment. Regardless of the severity of overbite, crossbite, or overjet, orthodontic patients with these malocclusions were treated in similar percentages at both practice types, because such problems are recognized by patients or their parents, who seek orthodontic treatment in any clinical setting. In addition, occlusal conditions such as increased overjet, tooth displacement, and increased overbite have a higher psychosocial impact than other conditions. ${ }^{42}$

In our study, almost $70 \%$ of orthodontic patients had great treatment need. A comparable $71.6 \%$ of patients were reported to need orthodontic treatment in a previous study of patients referred to $\mathrm{KAU} .{ }^{4} \mathrm{~A}$ higher percentage (83.2\%) of great treatment need was reported among referred Turkish children. ${ }^{22}$ However, a lower percentage (52.5\%) was reported among Saudi children who were about to undergo orthodontic treatment. ${ }^{28}$ In addition, $47.1 \%$ of referred Pakistani patients were clinically assessed as needing orthodontic treatment. ${ }^{40}$ These differences in orthodontic treatment need among orthodontically referred and treated individuals might be attributed to variability in the perceptions of patients or referring dentists, who may assess malocclusion with different prioritization of esthetic factors versus quantifiable treatment need.

Although the majority of patients in the present study required treatment, a difference in patients' distribution between KSU and private clinics was found. Approximately $77 \%$ of orthodontic patients treated at KSU clinics had great treatment need, compared with $58.5 \%$ at private clinics. This difference mainly results from differences in the severity of malocclusion in the sample population. Public institutions provide advanced services for patients with great treatment need. Patients with great treatment need often require a multidisciplinary approach with various hospital services that can only be provided at large institutions such as KSU. Approximately $42 \%$ of orthodontic patients treated at private clinics had no, little, or borderline treatment need, compared with $23 \%$ of patients at KSU clinics. This difference might be related to the payment method at the different clinic types. The desire of patients or their parents to receive treatment leads them to pay for treatment of conditions that have little treatment need. These results contradict those of Hassan, who found in 2006 that the proportion of patients with little to no treatment need was significantly higher at KAU clinics than at private clinics, whereas the proportion of patients with great treatment need was significantly higher at private clinics than at KAU clinics. ${ }^{4}$ Hassan's study included patients referred for orthodontic treatment, whereas our study included orthodontically treated patients. This difference in patients' stage of treatment may explain the contradictory results.

The majority of male patients with no, little, or borderline treatment need were treated at private clinics, whereas male patients with great need were treated at KSU clinics. This difference might be related to the fact that most male patients with little need were not accepted for treatment at KSU clinics and instead sought treatment at private clinics. Similarly, the majority of younger patients with no, little, or borderline treatment need were treated at private clinics, whereas younger patients with great need were treated at KSU clinics. Younger patients might convince their parents to seek and pay for orthodontic treatment at private clinics, even when there is little need for treatment.

Although most adolescents treated at KSU clinics were in great need of treatment, a considerable proportion (23\%) with no, little, or borderline treatment need were also treated. The free treatment provided at KSU clinics allows anyone to seek treatment, regardless of the severity of malocclusion. The treatment of patients with little treatment need might be related to sociopsychological patient needs. Patient perception concerning orthodontic treatment should not be ignored, and orthodontists should focus their attention beyond orthodontic mechanotherapy to the more subjective aspects of a patient's discomfort and attitude toward treatment. ${ }^{43}$ While the orthodontist prioritizes function and occlusion, the patient might perceive other factors to be equally important in initiating treatment. ${ }^{44}$

Although public clinics are tasked with providing care both to patients with true orthodontic treatment need and to those with needs that are more sociopsychological than functional, the long waiting lists for orthodontic treatment at KSU clinics indicate that the resources for orthodontic 
treatment are insufficient to accommodate the demand for services. Therefore, patient selection is necessary to ensure that treatment is provided to patients who need it the most, with consideration of the patient's self-perceived need.

National rules and regulations guiding the provision of public orthodontic services should be imposed and implemented based on evaluations such as occlusal indices. Orthodontic need assessment is not only important for treatment priority screening, but also useful for clinical intervention, dental-based programs, resource planning, and third-party funding. ${ }^{2}$ Experience with the use of such indices in other countries suggests that they play a valuable role in resource distribution and preparation, and result in more consistency in patient recognition and treatment referral. ${ }^{45}$ Accordingly, we recommend the use of the DHC of the IOTN as a screening tool to evaluate the waiting lists of patients seeking orthodontic treatment at KSU clinics.

Our study had some limitations, including missing data for some suitable patients and restricted access to the private clinics and patients' records, which limited the sample size. In addition, because this study was based on a limited sample and was collected from a single public academic institution, the results cannot be generalized to all orthodontically treated patients receiving care at public clinics. Further studies involving different public and private clinical settings are required.

\section{Conclusion}

Young Saudi patients receiving free treatment at public orthodontic clinics at KSU had more severe malocclusion and greater need of orthodontic treatment than the patients paying for treatment at private orthodontic clinics.

\section{Disclosure}

The authors report no conflicts of interest in this work.

\section{References}

1. Samsonyanová L, Broukal, Z. A systematic review of individual motivational factors in orthodontic treatment: facial attractiveness as the main motivational factor in orthodontic treatment. Int J Dent. 2014;2014:938274.

2. Poonacha K, Deshpande S, ShigliAnand L. Dental aesthetic index: applicability in Indian population: a retrospective study. J Indian Soc Pedod Prev Dent. 2010;28(1):13-17.

3. Hamdan AM. The relationship between patient, parent and clinician perceived need and normative orthodontic treatment need. Eur J Orthod. 2004;26(3):265-271.

4. Hassan AH. Orthodontic treatment needs in the western region of Saudi Arabia: a research report. Head Face Med. 2006;2:2.

5. Livas C, Delli K. Subjective and objective perception of orthodontic treatment need: a systematic review. Eur J Orthod. 2013;35(3):347-353.
6. Gomes MC, Clementino MA, Pinto-Sarmento TC, Costa EM, Martins CC, Granville-Garcia AF, Paiva SM. Parental perceptions of oral health status in preschool children and associated factors. Braz Dent J. 2015;26(4):428-434.

7. Borzabadi-Farahani A. A review of the evidence supportingthe aesthetic orthodontic treatment need indices. Prog Orthod. 2012;13(3):304-313.

8. Brook PH, Shaw WC. The development of an index of orthodontic treatment priority. Eur J Orthod. 1989;11(3):309-320.

9. Cons NC, Jenny J, Kohout FJ. Dental Aesthetic Index. Health Quest; Iowa City: College of Dentistry, University of Iowa; 1986.

10. Richmond S, Shaw WC, O'Brien KD, et al. The development of the PAR Index (Peer Assessment Rating): reliability and validity. Eur $J$ Orthod. 1992;14(2):125-139.

11. Daniels CP, Richmond S. The development of the index of complexity outcome and need (ICON). J Orthod. 2000;27(2):149-162.

12. Borzabadi-Farahani A. A review of the oral health-related evidence that supports the orthodontic treatment need indices. Prog Orthod. 2012;13(3):314-325.

13. Beglin FM, Firestone AR, Vig KW, Beck FM, Kuthy RA, Wade D. A comparison of reliability and validity of 3 occlusal indexes of orthodontic treatment need. Am J Orthod Dentofacial Orthop. 2001;120(3): 240-246.

14. Mandall NA, Wright J, Conboy F, Kay E, Harvey L, O’Brien KD. Index of orthodontic treatment need as a predictor of orthodontic treatment uptake. Am J Orthod Dentofacial Orthop. 2005;128(6):703-707.

15. Souames M, Bassigny F, Zenati N, Riordan PJ, Boy-Lefevre ML. Orthodontic treatment need in French schoolchildren: An epidemiological study using the index of orthodontic treatment need. Eur J Orthod. 2006;28(6):605-609.

16. Hammad MS, Awad MS. Orthodontic treatment need in Egyptian school children. Pediatr Dent J. 2011;21(1):39-43.

17. Athira S, Jayakumar HL, Chandra M, Gupta T, Swathy Anand PJ, Dithi C. Dental esthetic perceptions and orthodontic treatment needs among school children aged 9-18 years of South Bengaluru: a cross-sectional study. J Indian Assoc Public Health Dent. 2016;14(1):50-56.

18. Al-Sarheed M, Bedi R, Hunt NP. Orthodontic treatment need and selfperception of 11-16-year-old Saudi Arabian children with a sensory impairment attending special schools. J Orthod. 2003;30(1):39-44.

19. Kerosuo H, Al Enezi S, Kerosuo E, Abdulkarim E. Association between normative and self-perceived orthodontic treatment need among Arab high school students. Am J Orthod Dentofacial Orthop. 2004;125(3):373-378.

20. Hamdan AM. Orthodontic treatment need in Jordanian school children. Community Dent Health. 2001;18(3):177-180.

21. Borzabadi-Farahani A, Borzabadi-Farahani A, Eslamipour F. Orthodontic treatment needs in an urban Iranian population, an epidemiological study of 11-14 year old children. Eur J Paediatr Dent. 2009;10(2):69-74.

22. Uçüncü N, Ertugay E. The use of the Index of Orthodontic Treatment need (IOTN) in a school population and referred population. $J$ Orthod. 2001;28(1):45-52.

23. Fida M. Orthodontic treatment need in a sample Pakistani population. J Coll Phys Surg Pak. 2000;10:360-364.

24. Abdullah MS, Rock WP. Assessment of orthodontic treatment need in 5,112 Malaysian children using the IOTN and DAI indices. Community Dent Health. 2001;18(4):242-248.

25. So LLY, Tang ELK. A comparative study using the occlusal index and index of orthodontic treatment need. Angle Orthod. 1993;63(1):57-64.

26. CostHelper.Com. Available from: http://health.costhelper.com/braces. html,2009. Accessed April 28, 2016.

27. Dawoodbhoy I, Delgado-Angulo EK, Bernabé E. Impact of malocclusion on the quality of life of Saudi children. Angle Orthod. 2013;83(6):1043-1048.

28. Hassan A, Hassan M, Lenajwi A. Association of orthodontic treatment needs and oral health-related quality of life in Saudi children seeking orthodontic treatment. Patient Prefer Adherence. 2014;8:1571-1579. 
29. Jawad Z, Bates C, Hodge T. Who needs orthodontic treatment? Who gets it? And who wants it?. Br Dent J. 2015;218(3):99-103.

30. Pietila" T, Sintonen H, Pietila" I, Widstrom E, Varrela J, Alanen P. Cost and productivity analysis of orthodontic care in Finland. Community Dent Oral Epidemiology. 1998;26(4):283-288.

31. Väkiparta M, Kerosuo H, Nyström M, Heikinheimo K. Orthodontic treatment need from eight to 12 years of age in an early treatment oriented public health care system: a prospective study. Angle Orthod. 2005;75(3):344-349.

32. Abdellatif H, Al-Emran S. Attitude toward malocclusion and desire for orthodontic treatment among 9-17 year old Saudi. Saudi Dent J. 2005; 17(1):16-23.

33. Dogan AA, Sari E, Uskun E, Saglam AM. Comparison of orthodontic treatment need by professionals and parents with different socio demographic groups. Eur J Orthod. 2010;32(6):672-676.

34. Cardoso CF, Drummond AF, Lages EM, Pretti H, Ferreira EF, Abreu $\mathrm{MH}$. The dental aesthetic index and dental health component of the index of orthodontic treatment need as tools in epidemiological studies. Int J Environ Res Public Health. 2011;8(8):3277-3286.

35. Burden DJ, Pine CM, Burnside G. Modified IOTN: an orthodontic treatment need index for use in oral health surveys. Community Dent Oral Epidemiol. 2001;29(3):220-225.

36. Cousley R. IOTN as an assessment of patient eligibility for consultant orthodontic care. J Orthod. 2013;40(4):271-272.

37. Ireland AJ, Cunningham SJ, Petrie A, Cobourne MT, Acharya P, Sandy JR, Hunt NP. An index of orthognathic functional treatment need (IOFTN). J Orthod. 2014;41(2):77-83.
38. Borzabadi-Farahani A, Eslamipour F,Shahmoradi M. Functional needs of subjects withdentofacial deformities: a study using the index of orthognathic functional treatment need (IOFTN). J Plast Reconstr Aesthet Surg. 2016;69(6):796-801.

39. Albarakati SF. Self-perception of malocclusion of Saudi patients using the aesthetic component of the IOTN index. PODJ. 2007;27(1) $45-52$.

40. Siddiqui TA, Shaikh A, Fida M. Agreement between orthodontist and patient perception using Index of Orthodontic Treatment Need. Saudi Dent J. 2014;26(4):156-165.

41. Farias AC, Cangussu MC, Ferreira RF, Castellucci M. Occlusal characteristics and orthodontic treatment need in black adolescents in Salvador/BA (Brazil): an epidemiologic study using the dental aesthetics index. Dental Press J Orthod. 2013;18(1): $34 \mathrm{e} 1-34 \mathrm{e} 8$.

42. Bellot-Arcís C, Montiel-Company JM, Almerich-Silla JM. Psychosocial impact of malocclusion in Spanish adolescents. Korean J Orthod. 2013;43(4):193.

43. Lew KK. Attitudes and perceptions of adults towards orthodontic treatment in an Asian community. Community Dent Oral Epidemiol. 1993;21(1):31-35.

44. Josefsson E, Bjerklin K, Lindsten R. Factors determining perceived orthodontic treatment need in adolescents of Swedish and immigrant background. Eur J Orthod. 2008;31(1):95-102.

45. Shaw WC, Richmond S, O' Brien KD. The use of occlusal indices: a European perspective. Am J Orthod Dentofacial Orthop. 1995;107(1):1-10.
Clinical, Cosmetic and Investigational Dentistry

\section{Publish your work in this journal}

Clinical, Cosmetic and Investigational Dentistry is an international peer-reviewed, open access, online journal focusing on the latest clinical and experimental research in dentistry with specific emphasis on cosmetic interventions. Innovative developments in dental materials, techniques and devices that improve outcomes and patient satisfac-

\section{Dovepress}

tion and preference will be highlighted. The manuscript management system is completely online and includes a very quick and fair peerreview system, which is all easy to use. Visit http://www.dovepress. $\mathrm{com} /$ testimonials.php to read real quotes from published authors. 